\title{
MEETING REPORT Reflections on the CLIVAR Early Career Scientists Symposium 2016
}

Neil C. Swart ${ }^{1}$, Julius Busecke (iD $^{2}$, Gaby Langendijk ${ }^{3}$, Kevin A. Reed iD $^{4}$, Sarah M. Kang ${ }^{5}$, Erik Behrens ${ }^{6}$, Ariane Frassoni ${ }^{7}$, Noel C. Baker ${ }^{8}$, Jonathan V. Durgadoo ${ }^{8}$, Victor N. Dike ${ }^{9}$ and Debashis Nath ${ }^{10}$

We present a summary report of the CLIVAR Early Career Scientists Symposium, a three-day event associated with the CLIVAR Open Science Conference held in Qingdao, China during September 2016. The Symposium aimed to capture the ideas of early career researchers on pressing science priorities, imminent challenges, and emerging opportunities to help guide the future evolution of CLIVAR. We identified the need for improving process-based understanding and predictability of regional climate variability and change, moving toward seamless predictions, and improving and expanding global observations. We emphasize the need for increasingly open science, including universal access to data, code, and publications as well as opportunities for international cooperation and exchange. As the next generation of climate scientists, we are dedicated to overcome the challenges outlined in this summary and are looking forward to advancing CLIVAR's mission and activities.

npj Climate and Atmospheric Science (2018)1:6 ; doi:10.1038/s41612-018-0015-y

\section{INTRODUCTION}

Climate research is coordinated on the international stage by the World Climate Research Program (WCRP). The WCRP sets scientific goals and challenges for the community, coordinates scientific activities (e.g., the Coupled Model Intercomparison Project $($ CMIP) $),{ }^{1}$ and facilitates scientific exchange and collaboration. CLIVAR (Climate and Ocean: Variability, Predictability, and Change), is one of four core projects within WCRP, and focuses on the role of the ocean within the climate system. The CLIVAR Early Career Scientists (ECS) Symposium was held at the First Institute of Oceanography, Qingdao, China, on 18 September and 24-25 September, 2016-the weekends bounding the CLIVAR Open Science Conference (OSC). ${ }^{2}$ Participation was diverse, with 135 ECS attendees from 34 countries (Fig. 1).

The Symposium was held to inform ECS about the structure and activities of CLIVAR, to facilitate more active engagement of ECS in the OSC, and to develop an ECS perspective on the future of CLIVAR. On the occasion of the 20-year anniversary of CLIVAR, the Symposium constituted a unique opportunity for ECS to interact with their peers and senior scientists, to address research challenges of societal relevance, and to build lasting relationships and collaborations. In the following sections, we summarize the views of the Symposium participants on what they identify as pressing research questions, what challenges they face, how they believe CLIVAR should engage its audience, and their vision for the future of CLIVAR.

\section{PRESSING RESEARCH QUESTIONS AND GOALS}

The ECS identified the following research priorities: (1) improved understanding and predictability of regional climate variability and change, (2) improving process-based understanding, (3) seamless predictions, and (4) improved and expanded global observations.

While discussing regional climate prediction, we noted the importance of understanding the underlying dynamics and interactions of phenomena on timescales ranging from intraseasonal to multidecadal, with a particular emphasis on ENSO (EI Niño Southern Oscillation), its changes, teleconnections, and relationship to climate extremes. The distinction between forced and natural variability, and the influence of anthropogenic forcing on variability were also highlighted.

Improvements in model quality and predictive skill require the implementation of process-based understanding into model parameterizations. Making use of a single modeling system to make predictions across spatial and temporal scales (e.g., from weather to climate timescales; from local to global spatial scales), instead of using multiple different systems is know as "seamless prediction", and was recognized as a scientific priority. Such seamless prediction requires further work to improve understanding of how climate components interact across scales, and also to ensure that model parameterizations are appropriate or scale-aware (e.g., see ref. ${ }^{3}$ ).

Sustained, improved, and expanded observations were recognized as being our legacy to future generations of scientists. Continuing and expanding observations requires stability of longterm funding. Expansions would include accessing undersampled

\footnotetext{
${ }^{1}$ Canadian Centre for Climate Modelling and Analysis, Environment and Climate Change Canada, Victoria, BC, Canada; ${ }^{2}$ Lamont-Doherty Earth Observatory, Palisades, NY, USA ${ }^{3}$ World Climate Research Programme, Geneva, Switzerland; ${ }^{4}$ School of Marine and Atmospheric Sciences, Stony Brook University, Stony Brook, NY, USA; ${ }^{5}$ School of Urban and Environmental Engineering, Ulsan National Institute of Science and Technology, Ulsan, Republic of Korea; ${ }^{6}$ National Institute for Water and Atmospheric Research (NIWA), Wellington, New Zealand; ${ }^{7}$ National Institute for Space Research, Center for Weather Forecasting and Climate Studies, Cachoeira Paulista, São Paulo, Brazil; ${ }^{8}$ GEOMAR Helmholtz

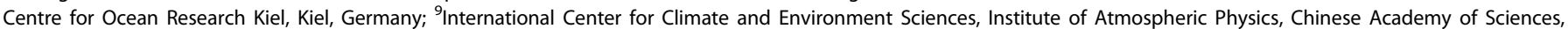
Beijing, China and ${ }^{10}$ Center For Monsoon System Research,Institute of Atmospheric Physics, Chinese Academy of Sciences, Beijing, China Correspondence: Sarah M. Kang (skang@unist.ac.kr)
}

Received: 30 December 2016 Revised: 17 September 2017 Accepted: 20 September 2017 Published online: 03 April 2018 


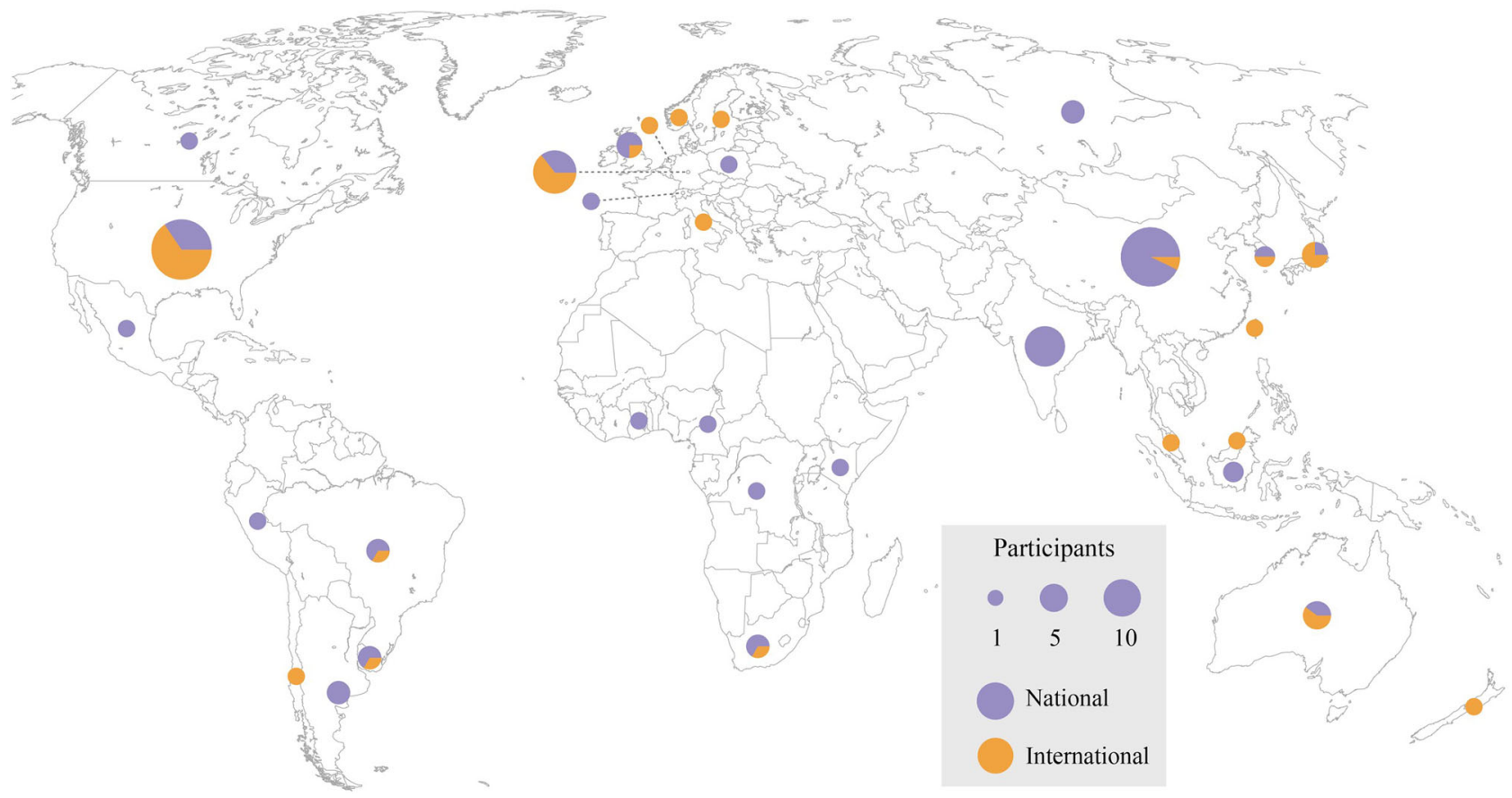

Fig. 1 Geographical distribution of ECS participants. Circle location and size indicate the number of participants currently affiliated with each country. The colors indicate if the participants are citizens of that country (national) or another country (international)

regions such as the deep ocean and under ice-covered ocean regions. Improvements could be made through increasing the precision, accuracy, and (cost) efficiency of the observing systems. There should be increased effort to identify important regions for focused future observations using current observations and model output (e.g., Tropical Pacific Observing System 2020; www. tpos2020.org/).

A few other topics were highlighted during discussions. These included challenges around the quantification of ocean carbon and heat uptake, and understanding the underlying processes. Other focus areas for the future included an increase in interdisciplinary research, with a specific mention of increased coordination with the paleo climate community, and the use of paleo-climate proxies to constrain climate models. Given the global scale of the problems, addressing these science priorities clearly requires international collaboration. In the following section, barriers and proposed solutions to such collaborations are explored.

\section{CHALLENGES TO INTERNATIONAL COLLABORATION AND POTENTIAL SOLUTIONS}

International collaboration was highlighted as instrumental to the success of the global science community, as the ECS recognized that climate challenges are not contained by political borders. The current generation of scientists has the responsibility to represent the interests of the global scientific community (Fig. 1), though challenges hinder our progress.

One major challenge is related to mobility. Difficulties in obtaining visas for conference attendance and short-term international exchanges, particularly post graduation, was a highly debated topic among Symposium participants. This particularly affects nationals from developing countries. Scientific progress at all levels is also hampered by political tensions and disputes between nations, which prevent the free exchanges of personnel and ideas or the conducting of scientific research. Climate science is a global enterprise, and while it is recognized that CLIVAR alone cannot directly influence national policies on immigration, it would be very helpful for the organization to take a leading role highlighting these issues and press for progress on the international stage through its parent organizations.

Asymmetries in availability and accessibility of scientific resources between nations were recognized as obstacles to collaboration. These include unequal access to data and journals, most prominent in developing countries (e.g., due to web filtering). Potential solutions include direct facilitation of twoway collaborative exchanges of scientists between countries, developing regional networks and capacity building in developing nations, and promoting networks to link scientists such as the Young Earth System Scientists (YESS) ${ }^{4}$ community and the Association of Polar Early Career Scientists (APECS, www.apecs. is). Such networks offer ECS online seminars, scientific exchange, and improved opportunities for communication between different disciplines and regions. To truly encourage a diverse global scientific discourse, the results, methods, and data have to be shared as freely and effectively as possible.

An overarching theme that emerged repeatedly at the Symposium was the need for increased openness and standardization of scientific content, ranging from open access to journals, to open-source code, to universal accessibility of research data. This so-called "open science" helps to ensure equal access across nations, and it increases the quality of our science by enabling reproducibility, improving usability, and allowing us to build on existing work. For example, a framework to share new parameterizations more easily among modeling groups could be one desirable outcome enabled by standardization. Such a mechanism could increase model diversity, and enable more rigorous intercomparisons. Similarly, data standardization commonly practised in modeling (e.g., CMIP), should be extended more broadly to openly shared observational products (e.g., obs4mips). ${ }^{5}$ By data standardization we mean common file formats and conventions, variable names, and units enabling analysis in a variety of model and observational setups, preferably without loss of information by regridding procedures. Organizations such as CLIVAR are ideally positioned to establish such frameworks, which enable standardization and sharing. In summary, we believe that it is the role of CLIVAR to facilitate and encourage "open science" wherever possible. 


\section{ENGAGING THE AUDIENCE OF SCIENCE INFORMATION}

During the Symposium it was recognized that there are many opportunities for scientists to engage with information users, ranging from education to science-policy interfaces, underscoring the responsibility of scientists to communicate their output.

Education at all levels, from school children to senior citizens, was seen as key to engaging the audience of information produced by the climate science community. Additionally, several groups mentioned the need for the implementation of basic climate science into the core curriculum at university (or even primary and secondary schools) level, to create a common knowledge base throughout all academic disciplines.

The importance of two-way communication between scientists and users was highlighted. The collaboration between forecasters and users within NOAA's (National Oceanic and Atmospheric Administration) Regional Integrated Sciences and Assessments (RISA) program is one specific example. Directly involving nonscience communities in the crafting of scientific questions and information co-production was identified as one of the best ways to achieve interaction, and this could also include active participation of the public via "citizen science."

Accurately conveying our scientific findings to the public and policy makers requires us as scientists to be directly involved in the communication process. The current generation of scientists should embrace the wealth of social media platforms for the dissemination of this information. Given the general lack of communications strategies within the natural sciences, CLIVAR could consider offering educational opportunities on effective communication. One practical suggestion was to create highly visible online platforms for short multimedia presentations explaining our science, similar to "APECS Frostbytes." An increased focus on these "soft skills" will help to increase our effectiveness in clearly laying out the importance and consequences of our science.

\section{CONCLUSIONS}

The success of the ECS Symposium was celebrated by the early career attendees and senior scientists alike. The Symposium provided a valuable networking and learning opportunity for early career researchers. More significantly, however, the Symposium raised the visibility of the early career segment of the community and gave us a real voice in CLIVAR OSC. Furthermore, the Symposium provided the opportunity for ECS to provide feedback to the broader CLIVAR science plan and cemented a platform for ECS to be actively involved in the future development of CLIVAR. The Symposium recognized climate and ocean science as truly international activities, revealing stronger challenges for international collaboration than many participants initially expected. We have suggested ways to facilitate coordination and improve our science in the service of society. The next generation of climate scientists is dedicated to overcome the challenges outlined in this summary and are looking forward to advancing CLIVAR's mission and activities.
Data availability

The data in Fig. 1 can be obtained from https://github.com/ jbusecke/NPJCLIMATSCI-00023R1_supplementary_figure1.

\section{ACKNOWLEDGEMENTS}

On behalf of the ECS participants, we would like to thank the First Institute of Oceanography in Qingdao for hosting the Symposium. We appreciate the hard work of the ECS organizers, local organizing committee, and scientific organizing committee (http://old.esaconferencebureau.com/2016-events/16c04/ecs-symposium), volunteers, and the CLIVAR International Project Office and Scientific Steering Group in facilitating and supporting the Symposium. We would like to thank the World Climate Research Program (WCRP) for providing the broader framework around the conference and for the partial financial support for ECS participants to join the Symposium and OSC.

\section{AUTHOR CONTRIBUTIONS}

N.C.B. and J.V.D posed the questions that formed the basis of the manuscript. N.C.S. and J.B. took the lead in writing the manuscript. J.B. produced Figure 1. All authors provided critical feedback and helped shape the manuscript.

\section{ADDITIONAL INFORMATION}

Competing interests: The authors declare no competing interests.

Publisher's note: Springer Nature remains neutral with regard to jurisdictional claims in published maps and institutional affiliations.

\section{REFERENCES}

1. Taylor, K. E., Stouffer, R. J. \& Meehl, G. A. An overview of CMIP5 and the experiment design. Bull. Am. Meteorol. Soc. 93, 485-498, (2012).

2. Stammer, D., Bracco, A. \& Detemmerman, V. Climate and ocean science builds for the future. Earth \& Space Science News 98. https://doi.org/10.1029/2017EO073225 (2017).

3. Arakawa, A. \& Wu, C. -M. A unified representation of deep moist convection in numerical modeling of the atmosphere. Part I. J. Atmos. Sci. 70, 1977-1992 (2013).

4. Rauser, F. et al. Earth System Science Frontiers: An early career perspective. Bull. Am. Meteorol. Soc. 98, 1120-1127, (2017).

5. Teixeira, J. et al. Satellite observations for CMIP5: The genesis of Obs4MIPs. Bull. Am. Meteorol. Soc. 95, 1329-1334 (2014).

\footnotetext{
Open Access This article is licensed under a Creative Commons Attribution 4.0 International License, which permits use, sharing, adaptation, distribution and reproduction in any medium or format, as long as you give appropriate credit to the original author(s) and the source, provide a link to the Creative Commons license, and indicate if changes were made. The images or other third party material in this article are included in the article's Creative Commons license, unless indicated otherwise in a credit line to the material. If material is not included in the article's Creative Commons license and your intended use is not permitted by statutory regulation or exceeds the permitted use, you will need to obtain permission directly from the copyright holder. To view a copy of this license, visit http://creativecommons. org/licenses/by/4.0/.
}

(c) The Author(s) 2018 